\title{
PSICOTERAPEUTAS, TRABALHO EM EQUIPA E INTEGRAÇÃO EM PSICOTERAPIA
}

\author{
Isabel Gonçalves e Hans Welling
}

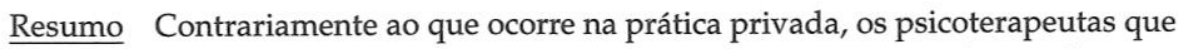
trabalham em meio institucional encontram-se menos isolados e podem, pelo menos potencialmente, trabalhar em equipa. No Núcleo de Aconselhamento Psicológico (NAP) do Instituto Superior Técnico, é exactamente isso que acontece - é constituído, em permanência, por uma equipa de seis a oito elementos, oriundos de diferentes orientações teóricas, que procuram trabalhar num modelo integrativo. As orientações teóricas de base representadas no serviço incluem a cognitiva-comportamental, a experiencial, a interpessoal e a familiar sistémica. Os autores propõem-se reflectir sobre o modo como o trabalho em equipa permite prevenir o stress e o esgotamento dos terapeutas. Referem-se ainda a alguns aspectos do funcionamento da equipa, incluindo a supervisão e a intervisão, a partilha e a intimidade, a co-terapia, o treino e as actividades de "construção" da equipa, a comunicação e a gestão de conflitos, as rivalidades, o planeamento, a resolução de problemas, a liderança, e ainda a partilha de objectivos e tarefas no seio da equipa. Esta exploração tem ainda como objectivo estimular a reflexão sobre uma hipótese que julgamos útil para o "movimento integrativo, " em geral, e para os psicoterapeutas interessados em trabalhar num quadro integrativo, em particular: poderá o trabalho em equipa promover/facilitar uma atitude integrativa em psicoterapia? Como? Como poderão os clínicos portugueses, nomeadamente os que trabalham em contexto institucional, tirar partido desta "oportunidade especial"?

Palavras-chave Psicoterapeutas, trabalho em equipa, integração.

\section{Introdução}

Uma suposição de base dos movimentos integrativo e ecléctico é a de que trocas dialécticas entre diferentes orientações teóricas serão mais provavelmente conducentes ao progresso científico do que o isolamento ideológico (Garfield \& Kurtz, 1977; Norcross \& Prochaska, 1988, citados por Mahoney et al., 1989). Esta afirmação, que pode sustentar a pesquisa de diferenças e semelhanças entre orientações teóricas distintas, também inspirou a nossa reflexão: se opusermos à prática clínica em contexto privado, relativamente isolada (também 
provavelmente de um ponto de vista "ideológico"), uma prática num contexto institucional, dentro de uma equipa coesa, onde possam estar representadas diversas orientações teóricas e onde as trocas "dialécticas" possam ser, também, mais frequentes, provavelmente vamos identificar um contexto conducente à adopção de uma atitude integrativa em psicoterapia.

Partimos da experiência de prática clínica num contexto institucional particular - o Núcleo de Aconselhamento Psicológico (NAP) do IST — e da constatação de que, progressivamente e, em particular, relativamente aos casos clínicos com diagnóstico de eixo II (DSM-IV) ou com co-morbilidade, fomos adoptando (como equipa mas também individualmente) uma abordagem cada vez mais integrativa na nossa prática clínica quotidiana, o que atribuímos, pelo menos em parte, ao contacto diário com colegas de orientações teóricas de bases distintas, em interacção próxima no seio de uma mesma equipa.

O intuito não é o de facultar "evidências empíricas" que suportem as nossas observações práticas, no entanto sentiremos ter alcançado o nosso objectivo se as reflexões seguintes servirem os inúmeros colegas que, na sua prática profissional e institucional, se encontram a trabalhar em equipas constituídas por profissionais de orientações teóricas distintas, tanto mais que não encontrámos qualquer referência, na literatura, ao papel que este tipo de contexto poderá ter tido no "movimento" da integração em psicoterapia. Assim, propomo-nos rever alguns dados da literatura que suportam a importância do trabalho em equipa, nomeadamente na prevenção do stress e burnout dos terapeutas, e, mais especificamente, explicitar os aspectos que, acreditamos, podem facilitar o estabelecimento de um clima de trabalho que promova a adopção de atitudes e práticas clínicas mais integrativas.

\section{Contexto institucional}

O NAP iniciou as suas actividades em Maio de 1993, com apenas um terapeuta, um dos autores do presente artigo. No entanto, o número de utentes do serviço triplicou em apenas dois anos de funcionamento, evidenciando a necessidade premente da existência deste tipo de serviços nas universidades portuguesas. Assim, sete anos depois do seu início, a equipa do NAP éjá constituída por dois psicólogos a tempo inteiro e por quatro psicólogos a meio tempo, que apresentam alguma diversidade no seu treino de base: cognitivo-comportamental, sistémico, experiencial e interpessoal, contudo todos interessados nas questões da integração em psicoterapia.

$\mathrm{O}$ contexto de trabalho em que se desenrolam as actividades da equipa do NAP parece-nos determinante, quer para a compreensão do "clima" que se criou e nos parece facilitador de uma "atitude pró-integração em psicoterapia", quer para a identificação dos "elementos activos" que, do nosso ponto de vista, mais poderão ser responsáveis pela adopção dessa atitude. 
O objectivo do NAP, tal como definido pela "Estrutura e Organização dos Serviços de Acção Social do IST" (CDIST, Junho de 1998), consiste em "promover o bem-estar psicológico da população do IST, proporcionando aos utentes atendimento especializado e específico nas áreas da orientação e aconselhamento, em situações de crise, e de terapia, em caso de perturbações diagnosticadas. Pode também organizar acções de formação para estudantes, abrangendo áreas como métodos de estudo ou gestão de carreira, por exemplo".

Os objectivos definidos e aceites para o NAP são, naturalmente, complexos, na medida em que se encontram na interface entre o trabalho estritamente terapêutico (já de si bastante sofisticado) e o trabalho institucional (particularmente difícil quando o discurso dos terapeutas parece tão diferente do discurso de quem gere a universidade), o que obriga a uma constante negociação das estratégias que, a cada momento, permitem alcançar os objectivos mutuamente acordados. Estas dificuldades funcionaram até aqui, e felizmente, como factor de promoção da coesão do grupo.

Ao reflectirmos sobre as actividades desenvolvidas no NAP durante os sete anos que passaram desde a sua criação, concluímos que um modelo interventivo integrativo é o mais adequado à intervenção com estes "jovens inteligentes, que estão prontos para fazer uso da terapia" (Veasey, 1997), "numa fase inicial do aparecimento de dificuldades e num estádio de menor gravidade das mesmas, havendo por isso a promessa de benefícios praticamente imediatos" (Figge, 1996). Actualmente, o nosso trabalho clínico pode ser descrito como de orientação comportamental-cognitiva de base integrativa (complementaridade paradigmática) (Gonçalves \& Vasco, 1997; Gonçalves \& Vasco, este número), sobretudo no que diz respeito à intervenção com clientes que apresentam perturbações do eixo II ou co-morbidez entre esta e uma ou mais perturbações do eixo I do DSM-IV.

\section{Trabalho em equipa e prevenção do esgotamento}

Uma característica que todos os elementos da equipa têm em comum é o empenho nesta "profissão impossível" (Freud, 1937/1964, citado por Sussman, 1995), conduzida inevitavelmente por pessoas "perfeitamente possíveis". Na raiz desta aparente contradição encontra-se aquele que é, provavelmente, considerado o "risco número um" e a maior fonte de stress identificada pelos que desempenham esta profissão: o isolamento (Bermak, 1977; Deutsch, 1984; Goldberg, 1986; Hellman, Morrison \& Abramowitz, 1986; Kotler, 1986; Tryon, 1983a, citados por Guy, 1987).

A especificação de todos os aspectos de que o isolamento se reveste, nesta profissão (Guy, 1987) parece-nos necessária, na medida em que não pretendemos afirmar que o trabalho em equipa pode pôr fim a algo que é tão intrínseco ao 
próprio desempenho da actividade, ainda que possa contribuir para atenuar algumas das suas consequências mais negativas.

Podemos, assim, identificar: (a) isolamento físico (tipicamente, a actividade da psicoterapia decorre numa sala fechada); (b) isolamento dos colegas, família e amigos (é do conhecimento dos colegas, familiares e amigos de qualquer terapeuta, que a interrupção de uma sessão apenas pode ocorrer em circunstâncias muito especiais, e ninguém aparece no local de trabalho de um psicoterapeuta apenas para socializar); (c) isolamento do mundo exterior (quer em termos de acontecimentos a nível nacional ou internacional, quer porque "a própria natureza do trabalho do terapeuta resulta num isolamento geral e quotidiano das pessoas emocionalmente 'saudáveis'" - Chessick, 1978, citado por Guy, 1987); (d) isolamento derivado da inactividade física compulsiva; (e) isolamento derivado da necessidade de manter a confidencialidade ("a aura de mistério que rodeia o terapeuta isola-o do suporte da família e dos amigos", Guy, 1987); (f) isolamento resultante da obediência estrita a um horário; $(\mathrm{g})$ isolamento psicológico resultante da necessidade de contenção por parte do terapeuta que não pode, tipicamente, revelar informações de natureza pessoal, que deve praticar algum controlo emocional e que frequentemente serve de "contentor" para as idealizações dos seus clientes e para as suas desqualificações (muitas vezes alternadamente); (h) isolamento psicológico resultante do carácter transitório da relação terapêutica, que inevitavelmente (e felizmente para o cliente) termina, tornando evidente para o terapeuta o carácter ilusório da intimidade que se estabeleceu; (i) isolamento psicológico resultante da competição profissional, que frequentemente impede os terapeutas de partilharem no seio da sua comunidade as suas dificuldades do foro íntimo; e, finalmente, (j) isolamento psicológico resultante da necessidade de estar à altura do estereótipo do terapeuta como um indivíduo equilibrado do ponto de vista emocional.

Naturalmente, o isolamento, tendo embora uma grande responsabilidade no aparecimento de stress e, posteriormente, no possível esgotamento, entre os terapeutas, não será o único factor que podemos identificar; existem outros: (a) a existência ou ausência de um bom suporte social (família e amigos); (b) as tarefas de desenvolvimento e os acontecimentos de vida (casamento, divórcio, nascimento de um filho, morte de um familiar próximo) com que o terapeuta se confronta, bem como a satisfação/insatisfação com as condições de trabalho, são também factores a tomar em consideração.

Em virtude da diversidade das fontes de stress possíveis de identificar, não é de surpreender que a prática da psicoterapia confronte os terapeutas com alguns perigos bastante significativos: uma elevada incidência de doença mental (sobretudo de depressão), abuso do álcool e de drogas, comportamentos sexuais inadequados e mesmo suicídio (Guy, 1987; Kilburg, Nathan \& Thorensen, 1986; Sussman, 1992, citados por Sussman, 1995).

Além do mais, o stress, a insatisfação com a profissão, a dependência do trabalho e o esgotamento tornaram-se assuntos centrais para as profissões de ajuda (Cherniss, 1980; Farber, 1985; Farber \& Heifetz, 1982; Freudenberger, 1974; 
Freuenberger \& Robbins, 1979; Prochaska \& Norcross, 1983; Wood, Klein, Cross, Lammers \& Elliot, 1985, citados por Sussman, 1995).

Por último, é ainda importante salientar que o trabalho psicoterapêutico pode ter um impacte negativo na relação conjugal (Bermack, 1977; Cray \& Cary, 1977; Farber, 1985, citados por Sussman, 1995), nas relações entre pais e filhos (Cray \& Cray, 1977; Henry, Sims \& Spray, 1973; Maeder, 1989, citados por Sussman, 1995; Guy, 1987) e nas amizades e vida social por geral (Burton, 1975; Guy, 1987; Freudenberger \& Robbins, 1979, citados por Sussman, 1995). "O esgotamento (não surpreendentemente) atinge proporções endémicas nas profissões de ajuda" (Grosch, \& Olsen, 1995).

Ainda que alguns autores (Guy, 1987; Kottler, 1986; Kottler \& Blau, 1989; Spurling \& Dryden, 1989; Sussman, 1995) se refiram, mais ou menos sumariamente, aos factores etiológicos - i.e., da história de desenvolvimento dos psicoterapeutas - que poderăo agir como facilitadores dos processos de esgotamento dos terapeutas - nomeadamente: (a) a "sensação de isolamento relativamente aos outros e consequente necessidade de proximidade; (b) o ter desempenhado na família de origem um papel de prestação de cuidados; (c) o ter sido emocionalmente ferido e desejar dar aos outros o que se teria precisado para si próprio; (d) a necessidade de reconhecimento"; (e) o "ser curioso, capaz de ouvir os outros, bom comunicador, empático, com bom insight emocional, introspectivo, capaz de autonegação, tolerante relativamente à ambiguidade, capaz de expressar afectos positivos, confortável com o exercício do poder, tolerante relativamente à intimidade e com sentido de humor", e ainda a "necessidade de conexão emocional e intimidade"; (f) o "narcisismo"; (g) o "endoutrinamento, desde a mais tenra infância, no papel de salvador ou mediador familiar, no respeito pelo poder nas relações interpessoais e na necessidade de ser bem sucedido", paradoxalmente, ou talvez não, estes mesmos factores podem ser também responsáveis pelo sucesso profissional dos terapeutas.

Contudo, a maioria dos autores centra-se mais na descrição dos "sinais de alarme do esgotamento no terapeuta" e na sugestão de um conjunto de "estratégias para evitar e lidar com o esgotamento". Freudenberger (1975, citado por Guy, 1987) recorda que a melhor estratégia de prevenção do esgotamento em psicoterapeutas consiste, precisamente, em alertá-los precocemente para os sintomas e riscos associados ao seu surgimento. Pelo que apresentamos, de seguida, os principais sinais de esgotamento no terapeuta, bem como as principais estratégias para o prevenir e combater.

Principais sinais de esgotamento no terapeuta (adaptado de Kottler, 1986):

- horror perante a perspectiva de fazer uma sessão;

- aborrecimento excessivo durante a sessão;

- cansaço;

- fantasias sobre a possibilidade de mudar de emprego ou de local de trabalho;

- resistência em falar socialmente a respeito do trabalho;

- relutância em consultar as mensagens no atendedor de mensagens ou no pager, ou em responder a essas mensagens; 
- ficar excessivamente satisfeito ou mesmo aliviado se um cliente cancela uma sessão;

- começar a notar um padrão sintomático consistente em todos os clientes, que inclui queixas como pessimismo, frustração e dúvidas sobre o processo terapêutico que, na realidade, expressam os sentimentos do próprio terapeuta;

- "escapismo" e dificuldade em se concentrar emocionalmente durante a sessão;

- dificuldade em se levantar de manhã e tendência para adiar o momento de iniciar a sessão;

- uso indiscriminado de psicofármacos;

- cinismo e falta de respeito relativamente aos clientes e às suas dificuldades;

- relutância em levar a cabo tarefas mais burocráticas;

- ocupação dos tempos de lazer com actividades essencialmente passivas como ver televisão;

- desaparecimento de uma vida social normal;

- incapacidade para reconhecer e confrontar os sinais de esgotamento.

Principais estratégias para prevenir e lidar com o esgotamento (adaptado de Kottler, 1986):

- impor limites ao número de horas diárias e semanais de prática terapêutica, bem como ao tipo de clientes que se aceitam (limitando, nomeadamente, os clientes com perturbações de personalidade severas, os clientes activamente suicidas e os clientes agressivos);

- rodear-se de relações pessoais que ofereçam um bom suporte emocional;

- aumentar as competências clínicas, procurando supervisão, assistindo a conferências e seminários profissionais, completando uma pós-graduação em terapia;

- gerir o tempo adequadamente, deixando espaços para actividades administrativas, preparação de sessões e supervisões, e, naturalmente, tempo para refeições, prática de exercício físico, tempos de lazer, etc.;

- combater a sensação de isolamento, criando oportunidades para socializar com colegas de profissão;

- procurar apoio terapêutico pessoal, quando necessário (é de notar que até ao presente os dados não são claros quanto à possibilidade de a terapia pessoal aumentar a eficácia dos terapeutas - no entanto, há que diferenciar entre a terapia pessoal que se faz como pré-requisito para a formação num dado modelo teórico e a terapia que se escolhe fazer por motivações de ordem pessoal);

- diversificar a actividade clínica de modo a evitar a monotonia - o aforismo "suficientemente difícil para ser desafiante mas não tão desafiante que possa ser esmagadora" traduz adequadamente o tipo de equilíbrio desejável;

- organizar períodos de férias frequentes, mesmo se curtos, e regulares;

- criar condições de solidão e privacidade, tão necessárias quando se é 
frequentemente "bombardeado" com experiências de elevada carga emocional;

- desdramatizar o insucesso terapêutico, aceitando as imperfeições como algo de intrínseco e inerente ao trabalho terapêutico;

- Grosch e Olsen (1995) sugerem ainda uma auto-reflexão em torno de questões relacionadas com a família de origem (quais as regras da família para lidar com o conflito? quais as regras explícitas e implícitas sobre o valor do trabalho?).

No NAP, onde se privilegia o trabalho em equipa e o estabelecimento de relações próximas entre os terapeutas, não é difícil manter algum tipo de monitorização dos sinais de esgotamento dos colegas. Adicionalmente, o funcionamento em equipa constitui um bom auxiliar na prevenção do isolamento e do stress dos terapeutas. Assim, passamos a explicitar o modo como tal se verifica na equipa.

Em primeiro lugar, identificámos as fontes de stress mais comuns: (a) o trabalho em excesso; (b) o número excessivo de clientes difíceis; (c) as pressões de tempo; (d) a incerteza económica; (e) a auto-responsabilização pelo bem-estar dos clientes (muito característica em terapeutas pouco experientes - Kottler \& Blau, 1989); (f) tentativas ou intenções suicidas por parte dos clientes; (g) encontros sociais relativamente inesperados com os clientes; $\mathrm{e},(\mathrm{h})$ resistência à mudança por parte dos clientes. Após esta identificação, procurámos limitar a incidência de alguns destes factores de stress, reduzindo, na medida do possível, o número de sessões, criando alguns períodos de pausa entre sessões e distribuindo os "clientes difíceis", equitativamente, por todos os elementos da equipa. Negociámos contratos a termo certo com o IST e estruturámos algumas supervisões em torno da ideia de responsabilidade pessoal do terapeuta.

Felizmente, outras fontes de stress (Mahoney, 1990) encontram-se relativamente ausentes no NAP, devido às próprias características do serviço: (a) isolamento (há três salas de sessão a funcionar, sendo bastante incomum que um terapeuta se encontre a trabalhar sozinho no serviço); (b) conflitos profissionais (o ambiente de trabalho é bastante agradável, com amplas oportunidades de socialização); (c) dúvidas sobre a eficácia da terapia (fazemos avaliações periódicas dos resultados das intervenções); (d) finalização prematura e cobrança aleatória das sessões (devido ao baixo custo das sessões, estas duas ocorrências são menos frequentes do que, por exemplo, na prática privada); (e) atrasos dos clientes (os traços e sintomatologia obsessiva dos clientes, frequentes na população-alvo, tornam este comportamento pouco frequente, exceptuando nos períodos de exames).

Finalmente, promovemos algumas estratégias que têm como objectivo explícito a prevenção do esgotamento dos terapeutas e colaboradores d'o serviço:

- os estágios oferecidos pelo serviço (sobretudo os académicos) são organizados de modo a que a exposição à terapia seja bastante gradual, começando pela integração na equipa (normalmente em pares), continuando 
com a observação de sessões realizadas por terapeutas seniores, com treino de competências através de role-playing, passando pela realização de sessões, primeiro de rastreio e com observação através de sala de visão num só sentido, depois sem observação, para só posteriormente se passar à realização de psicoterapia, começando com casos mais simples e com observação pelo supervisor, para terminar nos casos mais complicados e sem supervisão in loco;

alertamos os finalistas e recém-licenciados para alguns dos erros mais comuns em terapeutas inexperientes - problemas ao nível da responsabilidade (ou assumem total responsabilidade pela "cura" dos clientes, acreditando que uma palavra ou um gesto seu poderão causar um mal irreparável — sensação de omnipotência - ou se desresponsabilizam totalmente, explicando o que corre mal com a patologia do cliente); ao nível do uso das técnicas (e.g., dificuldades ao nível do contacto com o olhar, excessivo uso de questões fechadas que geram defensividade no cliente, dificuldade em tolerar os silêncios, tendência para confrontos excessivamente agressivos ou punitivos); ao nível do ritmo e do timing do processo terapêutico, errando os terapeutas mais jovens em ambos os extremos, i.e., intervindo com demaśiada rapidez ou com demasiada lentidão; ao nível da necessidade de aprovação pelo cliente (que pode levar o terapeuta inexperiente a aceitar pedidos ou exigências desadequadas por parte deste); e ainda problemas que resultam do facto de os terapeutas se verem confrontados com "temas" com que ainda não tiveram oportunidade de lidar nas suas próprias vidas; do facto de os terapeutas jovens não confiarem (ainda) na sua intuição, e dependerem excessivamente das avaliações e sugestões de outros colegas, ou até dos seus supervisores; do facto de os terapeutas inexperientes serem excessivamente confiantes ou excessivamente inseguros das suas capacidades.

Por último, em relação a problemas que resultam da excessiva impaciência dos terapeutas mais jovens (que desejam obter resultados rapidamente, e agem muitas vezes com precipitação, sem confiarem nas capacidades dos clientes para o crescimento e para a mudança), do facto de confiarem excessivamente nos "rótulos clínicos" que dão aos seus clientes, partindo para as sessões com uma ideia pré-concebida sobre quem é o cliente e qual o "tratamento" mais indicado para ele, esquecendo a velha máxima de que "cada caso é um caso", e ainda da sua dificuldade em lidarem com insucessos terapêuticos (adapt. de Kottler \& Blau, 1989):

- procuramos diversificar as actividades de todos os terapeutas, acrescentando e promovendo, para além das actividades de terapia individual, actividades de rastreio, de terapia conjugal e de grupo; incentivamos a elaboração e/ou a colaboração em projectos de investigação, a tradução de instrumentos de avaliação e materiais de apoio para os estudantes, a realização de acções de formação, de avaliação clínica e de diagnóstico, para além da colaboração na 
elaboração do relatório anual do NAP facilitamos ainda o desenvolvimento de projectos não clínicos, como sejam o "mentorado", o "treino assertivo", a "gestão de carreira" e os "métodos de estudo";

- atribuímos os casos mais complicados (eixo II do DSM IV ou co-morbilidade) aos terapeutas mais experientes. Embora nenhum dos terapeutas tenha mais de dez anos de experiência, dois deles completam este ano precisamente dez anos de prática. Num estudo de Orlinsky e colaboradores (1996) verificou-se que "quanto mais seniores os terapeutas, maior a capacidade para a mudança e crescimento pessoais, bem como para ultrapassar as suas limitações como terapeuta". Dryden e Spurling (1989) afirmam mesmo que "dificilmente será possível ser-se um terapeuta sofisticado com menos de dez anos de prática";

- incentivamos os terapeutas a procurar terapia pessoal sempre que o julguem necessário. Numa equipa de oito elementos, cinco estão neste momento a fazer terapia, e os restantes três mostram interesse em a fazer. Os terapeutas que se encontram em terapia fazem-no por motivações de ordem pessoal. Estes números vão no sentido dos obtidos no estudo internacional conduzido por Orlinsky e colaboradores (1996), no qual cerca de $80 \%$ dos terapeutas tinham realizado terapia pessoal;

- a componente de formação contínua é promovida pelo próprio serviço, quer através da divulgação de congressos, simpósios, encontros e seminários, quer através da ligação a uma organização profissional de terapia (Associação Portuguesa de Terapias Comportamental e Cognitiva), quer através da organização de acções de formação e sessões de discussão de artigos científicos. Naturalmente, a reflexão sistemática sobre o próprio serviço é uma constante em todas as actividades, nomeadamente através da emissão de relatórios anuais de avaliação (Gonçalves, 1995, 1996);

- estão planeados momentos de pausa e reflexão, que coincidem frequentemente com os períodos de férias dos alunos (Natal, Verão e Páscoa), períodos durante os quais escolhemos interromper a actividade clínica por alguns dias;

- estão escalonadas supervisões quinzenais, tendo cada supervisão a duração média de quatro horas;

- mantemos bem presentes os "princípios éticos" que devem reger o trabalho dos terapeutas, bem como os procedimentos de emergência a seguir em casos de clientes com comportamentos anti-sociais, ou potencialmente homicidas e suicidas, mesmo que eles nunca venham a ocorrer.

Prevenção do esgotamento e desenvolvimento pessoal: o contributo das supervisões para a dinâmica da equipa

Asupervisão tem sido identificada como uma actividade particularmente eficaz na prevenção do esgotamento (Farber, 1983, citado por Guy, 1987), uma vez que 
constitui uma fonte de suporte, uma oportunidade para testar a realidade e para obter feedback. A supervisão proporciona ao terapeuta uma oportunidade de monitorizar e reduzir as fontes de stress e insatisfação associadas com uma série de características dos pacientes, do local de trabalho, etc. Proporciona ainda um contacto directo com colegas, com quem se podem partilhar reflexões a respeito das limitações da profissão, os insucessos terapêuticos, as limitações pessoais e os problemas comuns da prática terapêutica.

A supervisão de grupo, como formato específico de supervisão, tem obtido, desde os anos 60, grande popularidade, nomeadamente devido às numerosas vantagens que apresenta por oposição à supervisão individual: maior eficácia e economia, graças à integração do contributo dos pares e dos especialistas (Glickauf-Hughes \& Campbell, 1991). Por exemplo, Axelson (1967, citado por Glickauf-Hughes \& Campbell, 1991) põe a hipótese de que a supervisão de grupo permite reduzir a incongruência entre as autopercepções e a percepção dos outros, enquanto que Yogev (1982, citado por Glickauf-Hughes \& Campbell, 1991) a considera como uma estratégia de intervenção eficaz no desenvolvimento de aptidões terapêuticas e na promoção da consciência interpessoal.

Curiosamente, até 1991, a supervisão de grupo raras vezes foi investigada empiricamente, recebendo também pouca atenção no desenvolvimento formal de modelos de supervisão (Blocher, 1983; Holloway \& Johnston, 1985; Patterson, 1983, citados por Glickauf-Hughes \& Campbell, 1991), sendo (erroneamente, em nosso entender) considerada exclusivamente como uma variante da supervisão individual. Em 1996, no entanto, a incorporação do formato de "equipa de reflexão", quer na prática terapêutica, quer na prática de supervisão, tornou-se de tal forma popular que deixou de poder ser considerada como uma prática inovadora (Lowe \& Guy, 1996).

A supervisão de grupo pode, no entanto, permitir e até facilitar o desenvolvimento de um conjunto de condições que poderão ser potencialmente prejudiciais para o resultado final. Glickauf-Hughes e Campbell (1991) identificaram algumas dessas condições: competição entre supervisandos; acentuados sentimentos de vergonha; acentuada defensividade dos supervisandos; interferência na supervisão de outros elementos do grupo; normas de grupo não facilitadoras e maior explicitação das competências diferenciais dos vários elementos do grupo. As condições que descrevemos poderão aumentar os sentimentos de vulnerabilidade dos supervisandos, o que poderá ser particularmente complicado em supervisões de cariz mais experiencial.

No NAP, as supervisões são de grupo e envolvem todos os elementos da equipa, têm periodicidade quinzenal e a assiduidade é bastante regular. $O$ modelo mais comum é o da apresentação de casos, no entanto existem supervisões "especiais" e "extraordinárias" em que se faz mais um trabalho de role-playing, bem como de modelagem e treino de técnicas mais experienciais (Greenberg, Rice \& Elliott, 1993). Aliás, o modelo designado por Glickauf-Hughes e Campbell (1991) como "supervisão experiencial" parece ser o que melhor define o trabalho que temos vindo a desenvolver. 
Um problema que se coloca, no entanto, aos supervisandos, passa pelo facto de o supervisor ter também responsabilidades administrativas e/ou de coordenação no local onde os terapeutas prestam serviço, podendo estes não se sentir seguros para se expor emocionalmente (Zaro, Barech, Nedelman \& Dreiblatt, 1977). Este problema foi contornado ao longo dos anos, procurando o supervisor estar progressivamente mais atento (sensível) à vulnerabilidade dos supervisandos, e desenvolvendo-se um conjunto de normas facilitadoras do processo de supervisão: disponibilidade para correr riscos, encorajamento de uma partilha honesta de sentimentos, estruturação de feedbacks construtivos, reconhecimento e aceitação dos erros e, finalmente, estabelecimento de uma atmosfera de cooperação (seguindo o esquema proposto por Glickauf-Hughes \& Campbell, 1991).

A experiência entretanto adquirida pelos vários terapeutas e o seu contributo progressivamente mais activo na co-construção de um modelo de supervisão mais eficiente, tornaram o papel do supervisor bastante mais ténue, a tal ponto que actualmente falamos em intervisão mais do que em supervisão.

Gostaríamos de salientar ainda algumas das estratégias desenvolvidas ao longo dos anos pela equipa, com o objectivo de optimizar a supervisão, nomeadamente no que diz respeito à criação de um clima de maior segurança interpessoal:

- gestão dos feedbacks dos colegas, nomeadamente através de uma maior explicitação dos pedidos: "não quero sugestões de intervenção", "quero só que me ouçam", "quero que me façam perguntas", "ajudem-me a conceptualizar" ou "digam-me em que é que o meu estilo/história pessoal poderá estar a influenciar negativamente o meu trabalho com este caso";

- consideração crescente do quadro teórico em que cada terapeuta "opera" predominantemente, com a consequente adaptação dos feedbacks e até da linguagem usada, de forma a serem consistentes com esse enquadramento;

- atribuição de prioridade, em termos de supervisão, às situações de impasse terapêutico.

Existem ainda supervisões mais formais conduzidas por terapeutas seniores da equipa e dirigidas aos terapeutas juniores, no âmbito da situação de estágio (académico ou profissional).

\section{Promoção de uma atitude de integração em psicoterapia}

Que o trabalho em equipa contribui para a prevenção do esgotamento entre os terapeutas, bem como para o desenvolvimento pessoal dos mesmos, nomeadamente através do desenvolvimento de actividades de supervisão e 
intervisão, parece-nos neste momento claro, e parece-nos também que é legítimo inferir que a prática clínica daí resultante poderá ser também de melhor qualidade do que a prática clínica praticada em condições de maior isolamento, no entanto não fica ainda claro em que medida poderá o trabalho em equipa promover uma atitude de integração em psicoterapia.

Pensamos que a resposta a esta questão passa, necessariamente, pela definição do conceito de integração em psicoterapia, que pode fazer-se recorrendo a "caminhos" distintos, sendo os três predominantes: "os factores comuns, o eclectismo técnico e a integração teórica, colectivamente caracterizados por um desejo de olhar para além dos limites de uma teoria única e das técnicas que tradicionalmente lhe estão associadas, concretizando, no entanto, esse olhar de modos distintos e a diferentes níveis" (Norcross \& Newman, 1992, citados por Norcross \& Halgin, 1997).

A abordagem dos factores comuns procura identificar os "ingredientes" centrais partilhados por todos os modelos de terapia, com o objectivo eventual de criar tratamentos mais parcimoniosos e eficazes. O eclectismo técnico pressupõe a capacidade de o terapeuta seleccionar a melhor intervenção terapêutica para o cliente " $x$ " com a perturbação " $y$ ", tomando como ponto de partida a experiência clínica e a investigação empírica, funcionando, contudo, dentro de um modelo específico de intervenção. Na integração teórica, um ou mais modelos teóricos são sintetizados, inclusivamente a nível teórico, na esperança de que o resultado seja superior ao uso de cada uma das terapias aplicadas de forma isolada (Norcross \& Newman, 1992, citados por Norcross \& Halgin, 1997).

No NAP, a consideração de factores como a "aliança terapêutica" a "catarse", a "promoção de expectativas positivas" e a "aquisição e prática de novos comportamentos", e a sua inclusão, de forma explícita, nomeadamente nas supervisões da equipa, evidenciam a adopção de uma perspectiva integrativa e representam o "caminho" dos "factores comuns". A disponibilidade, no seio da equipa, de terapeutas com orientações teóricas de base distintas cognitiva-comportamental, experiencial, interpessoal e terapia familiar sistémica — facilita a selecção da técnica mais adequada para um determinado cliente e com uma determinada perturbação - com a vantagem adicional de não ser tão fácil que uma dada técnica possa ser usada "desgarrada"do seu contexto teórico-metodológico - e representa o "caminho" do "eclectismo técnico".

Os terapeutas da equipa estão familiarizados com, e aplicam na sua prática clínica, alguns modelos teóricos que podem considerar-se integrativos (e.g., Beutler \& Clarkin, 1990; Lazarus, 1981; Linehan, 1993; Prochaska, Norcross \& DiClemente, 1994). Além do mais, entreajudam-se sempre que existe alguma dúvida a respeito da articulação e aplicação destes modelos, e esta atitude, finalmente, representa o "caminho" da "integração teórica". Assim, pensamos ser seguro afirmar que o trabalho em equipa, em determinadas condições (que passamos a explicitar, a título de exemplo), promove uma atitude de integração em psicoterapia. 


\section{Estrutura e processo de grupo: uma descrição da equipa}

Moss (1981, citado por Kottler, 1986) considera o grupo como "uma tremenda força curativa, na medida em que proporciona uma sensaçăo de partillha e pertença a uma comunidade, um envolvimento relacional, e uma energia universal, dinâmica e focalizada de que todos os que a ele pertencem podem beneficiar". Identifica ainda alguns elementos-chave que devem fazer parte daquilo a que chama um "grupo transformacional": (a) várias pessoas "acordadas" multidimensionalmente, um local conducente a um processo inspirado; (b) empenhamento da parte dos participantes no sentido de se libertarem de antigos padrǒes, de confiarem e de estarem em conjunto; (c) a infusão de afectos positivos. O mesmo autor acredita ainda que estes grupos surgem espontaneamente nas organizaçōes, possivelmente obedecendo às mesmas regras que presidem à formação das amizades: "proximidade física, familiaridade, semelhança, complementaridade e potencial reforçador" (Porter \& Tomaselli, 1989), constituindo uma importante fonte de suporte e crescimento pessoal para o psicoterapeuta, tendo como enorme vantagem a sua existência num registo quotidiano.

Linehan (1993) vai um pouco mais longe, ao definir a importância do grupo (de supervisăo) no trabalho com perturbaçб̌es de personalidade, nomeadamente com os clientes borderline: "a equipa de aconselhamento ajuda a que cada terapeuta individual permaneça na relaçăo terapêutica, dando-lhe suporte e encorajando-o", afirmando mesmo a impossibilidade de fazer um trabalho de qualidade com este tipo de clientes caso não se possa recorrer a uma equipa "de suporte".

A estrutura de um grupo num contexto orientado para objectivos, consiste na organizaçăo de um conjunto de elementos pré-determinados, característicos de ou resultantes da interacção dos seus membros num dado momento no tempo (Rose, 1989). Passamos a descrever a estrutura e processo do grupo constituído pelos elementos da equipa do NAP.

\section{Coesđo}

A coesão do grupo consiste no grau em que os membros do grupo se sentem em sintonia, no respeitante aos objectivos ou em relação ao líder (Lott \& Lott, 1965, citado por Rose, 1989). A coesão é considerada um atributo fundamental, uma vez que parece estar correlacionada, em certas condiçôes, com a produtividade, a participaçăo, o auto-relato, a capacidade para assumir riscos, a assiduidade e outros aspectos vitais para o grupo (Stokes, 1983, citado por Rose, 1989).

A coesão no seio da equipa é elevada, como se pode verificar quer pelos laços de amizade e cumplicidade que se estabeleceram, quer pela aceitação e empenhamento de todos os membros nos objectivos da equipa e no serviço onde desempenham a sua actividade profissional; 


\section{Liderança}

“O líder do grupo é responsável por certificar-se de que os objectivos do grupo são alcançados e de que o grupo se mantém no processo, para além de ser responsável por manter um equilíbrio entre estes dois aspectos. É ainda da responsabilidade do líder criar as oportunidades e o treino necessários para que os outros elementos do grupo possam desenvolver capacidades de liderança" (Rose, 1989).

No NAP a liderança é assegurada, essencialmente, pela coordenadora, que foi também a fundadora do serviço - digamos, pois, que se trata de uma líder "natural" face ao contexto. As funções de liderança são frequentemente partilhadas com outros elementos da equipa, nomeadamente os "seniores", sobretudo para actividades como a supervisão e a orientação de estágios académicos e profissionais.

Existe uma atitude deliberada por parte da liderança, no sentido de usar quer estruturas de poder formais, quer estruturas de poder informais, num estilo democrático de grande sensibilidade face às situações problemáticas e face aos diferentes elementos da equipa.

Existem reuniões de equipa quinzenais, que servem propósitos de supervisão e intervisão, bem como de coordenação do trabalho dos vários elementos da equipa, e existem ainda reuniões anuais entre a coordenadora e cada um dos colaboradores, em que se faz uma avaliação qualitativa do trabalho desenvolvido em cada ano, sendo ainda oferecido algum apoio por parte da coordenadora no estabelecimento de objectivos profissionais explícitos para o ano seguinte, bem como na identificação de dificuldades e linhas de desenvolvimento pessoal consideradas apropriadas para cada terapeuta.

Quando julgado útil e/ou necessário, sugere-se a hipótese de iniciar uma terapia pessoal, no entanto, o timing para essa decisão e a escolha do modelo teórico apropriado para esse processo ficam inteiramente ao critério dos próprios terapeutas.

A liderança desempenha também funções de gestão de conflitos. Até muito recentemente estes não eram comuns, talvez devido a uma certa tendência dos membros para idealizarem a própria equipa. Esta situação não podia, no entanto, manter-se por muito mais tempo e, de certa forma, a organização de uma formação em "terapia de grupo" orientada por uma terapeuta de formação psicodinâmica acabou por funcionar como catalisador para que a equipa se desse conta da existência (inevitável) de rivalidades e da necessidade de as gerir adequadamente. Uma vantagem adicional desta nova "consciência" consistiu na emergência de uma liberdade ainda maior para cada um expressar as suas opiniões pessoais e a sua individualidade como terapeuta, sem receio de "danificar" a coesão do grupo ou de sentir a desaprovação do mesmo pelo simples facto de expressar opiniões diferentes.

Uma outra forma de entender esta mudança inclui a noção de que a equipa poderá vir a revelar-se, no futuro, ainda mais criativa. Na verdade, um excesso de coesão no seio do grupo pode conduzir a um "pensamento de grupo", que pode 
diminuir o potencial crítico dos seus membros, criar uma falsa sensação de optimismo, promover ilusões de unanimidade e, de uma forma geral, diminuir a eficácia dos processos de tomada de decisão.

A coesão traduz-se ainda pela preocupação de cada elemento quer com o seu próprio bem-estar, quer com o dos restantes colegas da equipa. Assim, os períodos de férias são organizados de forma a haver sempre alguém disponível para emergências, as refeições são frequentemente em comum, sobretudo quando alguém da equipa necessita de um apoio "especial" e, finalmente, está frequentemente alguém disponível para dar apoio a um colega, caso este tenha de fazer uma sessão particularmente extenuante do ponto de vista emocional (e.g., sessões com clientes suicidas);

Padrões de desempenho e procedimentos de tomada de decisão.

Considerando as dimensões da equipa, o grau de sofisticação do trabalho desenvolvido e as implicações práticas da abertura do serviço a estagiários oriundos do mundo académico e do mundo profissional, a coordenadora sintetizou, sob a forma de regulamento, um conjunto de procedimentos formais e técnicos que incluem:

- especificação dos objectivos do serviço;

- especificação do(s) modelo(s) teórico(s) adoptado(s);

- especificação dos recursos humanos afectos ao serviço e respectivas funções;

- localização e horário de funcionamento do serviço;

- especificação das tabelas de pagamento para os utentes;

- especificação das regras relativas à marcação de sessões, procedimentos de rastreio, gestão da lista de espera e organização dos processos clínicos;

- especificação de algumas regras de conduta profissional e de procedimentos a adoptar numa situação de crise;

- especificação dos principais momentos do processo terapêutico e dos instrumentos de avaliação usados no serviço.

Os padrões de desempenho que estas especificações, no fundo, traduzem, refinados e co-construídos ao longo dos anos por toda a equipa, encontram-se em revisão permanente e acabam por, de certa forma, traduzir importantes momentos de crescimento da equipa, para além de funcionarem de modo a permitirem o ajuste entre os recursos do serviço e as necessidades/disponibilidades dos vários elementos da equipa. Adicionalmente, contribuem para estabilizar as energias no seio do grupo, para promover a coesão e para optimizar o desempenho do serviço.

No NAP existe uma grande flexibilidade ao nível dos procedimentos de tomada de decisão, sendo precisamente esta flexibilidade que, a nosso ver, garante a possibilidade de inovar e de resistir num ambiente relativamente hostil, como ainda é o do aconselhamento a estudantes do ensino superior em Portugal. Assim, as linhas estratégicas para o funcionamento do serviço são definidas em uma ou 
duas reuniões anuais realizadas em fins-de-semana, em que toda a equipa se reúne num clima de maior informalidade e sem pressões de tempo. Estas linhas estratégicas são depois implementadas e actualizadas ao longo do ano em encontros quinzenais que coincidem também com o espaço para a supervisão de casos clínicos.

As decisões quotidianas (e.g., relativas à gestão da lista de espera) são tomadas pela coordenadora, ainda que esta possa recorrer, e frequentemente recorra, a um ou outro elemento da equipa, caso o tema da decisão o justifique. As decisões relativas aos estagiários são tomadas pelos supervisores de estágio. Finalmente, as decisões clínicas são, evidentemente, tomadas por cada um dos terapeutas no espaço terapêutico, ainda que as linhas estratégicas que guiam essas decisões possam ser negociadas em supervisão (sobretudo em fases em que se registam impasses terapêuticos). As excepções a estes processos individuais de tomada de decisão clínica ocorrem nos processos de terapia de grupo, conjugal ou familiar, em que as decisões são, logicamente, negociadas entre os membros da equipa responsáveis pelo trabalho com o grupo, com o casal ou com a família.

\section{Conclusões}

Após termos descrito o funcionamento e estrutura da equipa, retomamos questão central de referência: "será que o trabalho em equipa facilita ou (mesmo) promove a integração em psicoterapia?", em caso afirmativo, então como funciona (i.e., ocorre em todo e qualquer contexto institucional, com toda e qualquer equipa clínica, com membros de toda e qualquer orientação teórica?) Será que podemos, de algum modo, potenciar o seu "poder integrativo"?

Acreditamos que a resposta à primeira questão é "sim", sobretudo se compararmos o trabalho num serviço, com as características que acima enunciámos, com a tradicional e isolada prática em clínica privada. As respostas às duas outras questões parecem-nos, no entanto, mais complexas, exigindo talvez uma investigação alargada, orientada simultaneamente por psicólogos sociais e por psicólogos clínicos, abrangendo simultaneamente vários contextos de trabalho - da prática privada ao trabalho institucional - começando aqui por incluir, naturalmente, todos os serviços e/ou clínicos que se autodefinam como integrativos e que estejam dispostos a partilhar o processo pelo qual acreditam que "chegaram" a uma atitude integrativa em psicoterapia.

No entanto, e partindo da experiência, descrita no presente artigo, vamos resumir os factores que acreditamos terem sido fundamentais na formação da nossa identidade como terapeutas integrativos.

(1) O clima de abertura que se vive na equipa parece ter facilitado uma atitude de aceitação face à diferença. Assim, as diferenças psicossexuais (género feminino, género masculino), as diferenças culturais (cultura portuguesa, cultura 
holandesa), as diferenças de estilo terapêutico (mais caótico e emocional, mais estruturado e didáctico), as diferenças teóricas (cognitivo-comportamental, sistémica, interpessoal, dinâmica), as diferenças técnicas, metodológicas e de formação académica, todas elas são aceites e até mesmo bem-vindas, num quadro onde as semelhanças também desempenham um papel não negligenciável. Assim, existem grandes semelhanças entre os elementos da equipa ao nível da idade (todos têm entre 25 e 35 anos), ao nível do estádio de desenvolvimento (todos são jovens adultos, a negociar tarefas como a intimidade, a vivência a dois, a constituição de uma família) e ao nível dos valores, objectivos de vida e atitude face à profissão.

O clima de proximidade afectiva que se vive também dá suporte a uma atitude mais experimental por parte dos elementos da equipa, que desta forma se sentem mais capazes de arriscar técnicas ou metodologias de intervenção oriundas de outras orientações teóricas que não a sua, sem perder de vista o contexto em que estas foram desenvolvidas, na medida em que há sempre colegas para clarificar dúvidas que surjam. Aliás, consideramos que a integração em psicoterapia se deve constituir tomando em consideração simultaneamente os factores que são comuns a todas as orientações teóricas (Norcross \& Halgin, 1997) e aqueles que, sendo específicos a uma orientação particular, se mostraram particularmente eficazes na intervenção com tipos de pacientes e/ou problemáticas específicas (e.g., terapia cognitivo-comportamental e terapia interpessoal dinâmica para o tratamento da depressão; exposição e prevenção da resposta no tratamento das perturbações obsessivo-compulsivas; programas de intervenção familiar no tratamento da esquizofrenia; terapia comportamental dialéctica para a perturbação borderline) (para uma revisão das intervenções terapêuticas empiricamente validadas, ver Roth \& Fonagy, 1996).

(2) A integração é também facilitada durante as supervisões: estas são estruturadas e conduzidas pelos autores do presente artigo, que são simultâneamente os terapeutas mais experientes da equipa, e que têm formações complementares de base cognitiva-comportamental e de base experiencial-interpessoal. Ambos contribuem para a identificação dos impasses terapêuticos, para a discussão de casos e para o planeamento das intervenções terapêuticas, num quadro em que a regra mais importante é a do respeito pelo estilo pessoal e preferências teóricas de cada terapeuta. No entanto, e cada vez mais, o grupo assume um formato de intervisão, em que cada terapeuta contribui com as suas próprias perspectivas teóricas, técnicas, metodológicas e experienciais na análise dos casos inscritos para supervisão. As leituras, a experiência clínica e o trabalho que cada um dos elementos da equipa vem realizando na sua própria terapia são cada vez mais evidentes, enriquecendo o trabalho clínico de todos e de cada um dos terapeutas, num clima que é sempre de cooperação, mesmo quando as rivalidades entre terapeutas se tornam explícitas.

(3) Todos os elementos da equipa estão bastante familiarizados com os dados da investigação sobre factores comuns (e.g., Weinberger, 1993) e sobre os diferentes 
modelos de integração em psicoterapia (e.g., Norcross \& Halgin, 1997), estando por isso mesmo sensibilizados, nomeadamente, para a importância da aliança terapêutica e das características pessoais do terapeuta para o resultado terapêutico (Horvath \& Symonds, 1991; Lambert, 1989), bem como para a importância de adoptar uma perspectiva integrativa, nomeadamente na intervenção com perturbações do eixo II ou em que exista co-morbidez. Atitude que é, aliás, característica de uma nova geração de terapeutas - mais interessados na eficácia da sua intervenção do que na defesa dogmática de qualquer modelo puro de terapia.

Aliás, em Portugal, os terapeutas mais jovens parecem ser mais integrativos (Vasco, Garcia-Marques, \& Dryden, 1992). O "esforço consciente" que os elementos da equipa assumem no sentido de adoptarem uma atitude integrativa no seu trabalho como terapeutas é reforçado pela insatisfação que todos sentem relativamente às limitações dos modelos teóricos de base em que foram treinados, bem como pelo facto de todos se encontrarem numa fase relativamente inicial das suas carreiras e, consequentemente, todos procurarem um modelo terapêutico com que se sintam confortáveis e que lhes permita serem eficazes no seu trabalho.

(4) Sempre que possível, os membros da equipa participam em actividades de treino, formais e informais, em diversos modelos teóricos, nomeadamente modelos que são já de natureza integrativa (e.g., Beutler \& Clarkin, 1990; Lazarus, 1981; Linehan, 1993; Prochaska, Norcross \& Diclemente, 1984), mostrando clara preferência por acções de formação com uma forte componente prática. As actividades de treino mais formais incluem seminários.

As actividades de treino mais informais incluem mini-acções de formação organizadas dentro da equipa, por elementos da equipa, dedicadas a temas do interesse simultaneamente do "formador" e dos "formandos". Incluem ainda a partilha de bibliografia julgada interessante, a organização de sessões de role-play e a discussão de sessões observadas através da sala de visão num só sentido.

(5) Todos os elementos da equipa pertencem à Society for the Exploration of Psychotherapy Integration, todos estão abertos e genericamente motivados para a necessidade de conduzir investigação em psicoterapia, e todos se disponibilizam para dar conta das suas aprendizagens e para as partilhar, explicitando-as sob a forma de artigos e relatórios que, por serem escritos em conjunto, permitem a criação de um vocabulário comum e um refinamento constante dos modos de intervir clinicamente.

(6) Oúltimo factor, que é talvez o mais importante, consiste no compromisso que todos os elementos da equipa estabeleceram com a sua profissão. Esta é a actividade profissional a que todos dão maior relevância e todos se imaginam a exercê-la para o resto das suas vidas. Um dos modos como os terapeutas se referem 
a este "enriquecimento pessoal" traduz-se pela sensação de viverem uma actividade privilegiada - nada parece comparar-se à possibilidade de assistirem à definição, reestruturação e expansão de um ser humano distinto e único — o cliente - ou ao compromisso, que frequentemente dura uma vida, no sentido de aceitarem uma posição de permanente desafio e crescimento pessoal. Não surpreende, por isso, que quanto mais experientes os terapeutas, maior a satisfação com a actividade terapêutica.

"Múltiplas e convergentes são as fontes que indicam que a pessoa do terapeuta está profundamente interligada com o resultado, reconhecendo-se a sua centralidade no processo de mudança. Nem a teoria nem as técnicas, apenas a sintomatologia do cliente se revela um determinante mais poderoso do que o terapeuta no processo de mudança terapêutica" (Dryden \& Spurling, 1989).

Como Goldberg (1990, citado por Lenson, 1994) muito adequadamente recorda, "a terapia é a mais humana das artes e das ciências. Muitos de nós esquecem-se rapidamente de que a fonte da nossa capacidade para tocar os outros reside, precisamente, na nossa humanidade" e, no entanto, é precisamente essa "humanidade" que confronta os terapeutas no exercício da sua actividade clínica com os maiores riscos, mas também com as maiores recompensas. É por isso justo que nos dediquemos ao estudo da pessoa do terapeuta. Recentemente, aliás, esta "tendência de investigação" tem vindo a receber a atenção não só de autores estrangeiros (e.g., Sussman, 1992, 1995; Dryden \& Spurling, 1989; Guy, 1987; Kottler, 1986; Kottler \& Blau, 1989; Orlinsky et al., 1996; Persons, 1984), mas também de nacionais (e.g., Vasco, 1993, 1994a, 1994b).

\section{Referências}

Beutler, L. E., \& Clarkin, J. F. (1990). Systematic treatment selection. Nova Iorque: Brunner / Mazel.

Dryden, W., \& Spurling, L. (Eds.) (1989). On becoming a psychotherapist. Londres e Nova Iorque: Tanistock / Routkedge.

Figge, P. (1996). Counselling institutions as academic service-centers: Advocating an integrated approach to counselling. Comunicação apresentada no congresso Guidance and Psychological Counselling in Higher Education: An European Challenge, Coimbra, Portugal.

Freeman, A., Pretzer, J., Fleming, B., \& Simon, K. M. (1990). Clinical applications of cognitive therapy. Nova Iorque: Plenum.

Freeman, A. (1992). The development of treatment conceptualisations in cognitive therapy. In A. Freeman \& F. M. Dattilio (Eds.), Comprehensive casebook of cognitive therapy (pp. 13-23). Nova Iorque: Plenum.

Glickauf-Hughes, C., \& Campbell, L. F. (1991). Experimental supervision: Applied techniques for a case presentation approach. Psychotherapy, 28, 625-635. 
Gonçalves, I. (1995). Relatório do trabalho desenvolvido no serviço de apoio psicológico ao longo do seu segundo ano de funcionamento. Objectivos e descrição SAP, tipo de clientes (pp. 23-25, 121-125, 128-133). Lisboa: UTL-IST

Gonçalves, I., (1996). O serviço de apoio psicológico do Instituto Superior Técnico: Balanço do trabalho realizado durante o ano de 1995. Lisboa: UTL-IST.

Gonçalves, I. C., \& Vasco, A. B. (1997). Paradigmatic complementarity: An integrative cognitive behaviorally based intervention for personality disorders. Comunicação apresentada na 13th Conference of the Society for the Exploration and Psychotherapy Integration, Toronto, Canada.

Gonçalves, I. C., \& Vasco, A. B. (2001). Estudo de caso de uma "perturbação borderline da personalidade" à luz do modelo de "complementaridade paradigmática". Psicologia, XV (1)

Grosh, W. N., \& Olsen, D. C. (1995). Prevention: Avoiding burnout. In M. B. Sussman (Ed.), A perilous calling - The hazards of psychotherapy practice. Nova Iorque: John Willey \& Sons.

Guy, J. D. (1987). The personal life of the psychotherapist. Nova Iorque: John Wiley \& Sons.

Horvath, A. O., \& Symonds, B. D. (1991). Relation between working alliance and outcome in psychotherapy: A meta-analysis. Journal of Counselling Psychology, 38, 139-149.

Kottler, J. A. (1986). On being a therapist. São Francisco: Jossey-Bass.

Kottler, J. A., \& Blau, D. S. (1989). The imperfect therapist. São Francisco: Jossey-Bass.

Lazarus, A. A. (1981). The practice of multimodal therapy. Nova Iorque: McGraw-Hill.

Lambert, M. J. (1989). The individual's therapist contribution to psychotherapy process and outcome. Clinical Psychology Review, 9, 469-485.

Lenson, E. S. (1994). Succeeding in private practice. Londres: Sage.

Linehan, M. M. (1993). Cognitive-behavioral treatment of borderline personality disorder. Nova Iorque: Guilford.

Lowe, R., \& Guy, G. (1996). A reflecting team format for solution-oriented supervision: Practical guidelines and theoretical distinctions. Journal of Systemic Therapies, 15, 26-45.

Mahoney, M. J., Norcross, J. C., Prochaska, J. O., \& Missar, C. D. (1989). Psychological development and optimal psychotherapy: Converging perspectives among clinical psychologists. Journal of Integrative and Eclectic Psychotherapy, 8, 251-263.

Norcross, J. C., \& Halgin, R. P. (1997). Integrative approaches to psychotherapy supervision. In C. E. Watkins (Ed.), Handbook of psychotherapy supervision. Nova Iorque: John Wiley \& Sons.

Omer, H. (1994). Critical interventions in psychotherapy. Nova Iorque: Norton.

Orlinsky, D. et al. (1996). The development of psychotherapists - II: Therapist's perspectives on professional growth. SPR Collaborative Research Network, manuscrito não publicado.

Persons, J. B. (1984). Cognitive therapy in practice. Nova Iorque: Norton.

Porter, R., \& Tomaselli, S. (1989). The dialectics of friendship. Londres: Routledge.

Prochaska, J. O., Norcross, J. C., \& Diclemente, C. C. (1994). Changing for good. Nova Iorque: William Monward.

Sussman, M. B. (Ed.) (1995). A perilous calling - The hazards of psychotherapy practice. Nova Iorque: John Willey \& Sons. 
Vasco, A. B. (1993). Resistência e erros inferenciais: Notas sobre as "perturbações" do psicoterapeuta. Psicologia, IX (1), 75-80.

Vasco, A. B. (1994a). Psicoterapeutas portugueses: Características demográficas, actividades profissionais, perspectivas teóricas e satisfação com o treino e com a carreira. Psicologia, IX (3), 405-428.

Vasco, A. B. (1994b). Aventuras e desventuras do psicoterapista no reino do amor. Comunicação apresentada no seminário "Do amor", Lisboa.

Vasco, A. B., Garcia-Marques, L., \& Dryden, W. (1992). Eclectic trends among Portuguese psychotherapists. Journal of Psychotherapy Integration, 4, 321-331.

Veasey, H. (1997). How can the student counselling service benefit the university community? Comunicação apresentada no First Portuguese Meeting of Counselling Services for University Students, Lisboa.

Yerushalmi, H. (1992). Psychoanalytic supervision and the need to be alone. Psychotherapy, 29, 262-268.

Zaro, J. S., Barech, R., Nedelman, B. J., \& Dreiblatt, I. S. (1997). A guide for begining psychotherapists. Nova Iorque: Cambridge University Press.

Psychotherapists, team-work and integration in psychotherapy

(abstract) Contrary to what is usual in private practice, psychotherapists working in an institution are less isolated and more often work as a team. This is the case at the Counseling Center, Technical University, where a team of 6 to 8

psychotherapists, who started with different theoretical orientations, including the cognitive-behavioral, the experiential, the interpersonal and the systemic family therapy, try to work together. The authors will explain how teamwork helps prevent stress and burnout among therapists. The authors will also explore some aspects of the work of this recently created team (2-5 years), including: leadership, supervision and intervision, self-disclosure, sharing and intimacy, co-therapy, training and team-building activities, communication and conflict management, rivalry, planning, problem-solving and shared goals and tasks. This exploration is meant to stimulate reflection upon an idea we believe might be useful for the "integrative movement," in general, and for clinicians interested to work within an integrative framework, in particular: can teamwork facilitate psychotherapy integration? how? How could we take advantage of this "special opportunity"? 